\title{
Physical activity and dentate gyrus volume in pediatric acquired demyelinating syndromes
}

Giulia Longoni, MD, Robert A. Brown, PhD, Berengere Aubert-Broche, PhD, Stephanie A. Grover, MSc, Helen M. Branson, MD, Dumitru Fetco, MD, Amit Bar-Or, MD, Ruth Ann Marrie, MD, PhD, Robert W. Motl, PhD, D. Louis Collins, PhD, Sridar Narayanan, PhD, Douglas L. Arnold, MD, Brenda Banwell, MD, and E. Ann Yeh, MD

Neurol Neuroimmunol Neuroinflamm 2018;5:e499. doi:10.1212/NXI.0000000000000499

\section{Abstract \\ Objective}

To assess the association between daily moderate-to-vigorous physical activity (MVPA) and dentate gyrus volume (DGv) in pediatric patients with acquired demyelinating syndromes (ADSs) of the CNS.

\section{Methods}

Cross-sectional analysis of accelerometry ( 7 days) and research protocol MRI data from 12 pediatric MS and 18 children with monophasic ADS (monoADS). Total brain and DGv were quantified using standardized methods. The association of daily minutes of MVPA with normalized DGv (nDGv) was assessed using multivariable generalized linear models.

\section{Results}

Median (interquartile range) MVPA was lower in MS patients [9.5 (14)] and exhibited less variation than in monoADS patients $[24.5(47)]$. nDGv did not differ significantly between groups [mean $\mathrm{nDGv}(\mathrm{SD})\left[\mathrm{cm}^{3}\right]$ : MS $0.34(0.1)$; monoADS $\left.0.4(0.1) ; p=0.100\right]$. In the monoADS group, every 1-minute increase in MVPA was associated with a $2.4-\mathrm{mm}^{3}$ increase in $\mathrm{nDGv}(p=0.0017)$, an association that was independent of age at incident demyelination, time from incident demyelination, sex, and brain white matter T2 lesion volume. No significant association was found between MVPA and $\mathrm{nDGv}\left(-2.6 \mathrm{~mm}^{3} / \mathrm{min}, p=0.16\right)$ in the MS group.

\section{Conclusions}

Higher MVPA associates with greater nDGv in children who have recovered from monophasic demyelination. Larger studies are required to determine whether MVPA can promote regional brain development, or limit tissue damage, in youth with MS.

\author{
Correspondence \\ Dr. Yeh \\ ann.yeh@sickkids.ca
}




\section{Glossary}

ADS $=$ acquired demyelinating syndrome; CES-DC $=$ Centre for Epidemiological Studies Depression Scale for Children; $\mathbf{C P M}=$ counts per minute; DG = dentate gyrus; DGv = dentate gyrus volume; DMT = disease-modifying treatment; EDSS = Expanded Disability Status Scale; LV = lesion volume; monoADS = monophasic ADS; MVPA = moderate-to-vigorous physical activity; $\mathbf{n D G} \mathbf{v}=$ normalized DGv.

The hippocampus is responsible for memory and spatial processing. Hippocampal atrophy is observed in adults and children with MS and is associated with impaired visuospatial and episodic memory. ${ }^{1}$ Recently, moderate-to-vigorous physical activity (MVPA), via its pleotropic effects, has been associated with improved memory performance and increased hippocampal volume in healthy adults ${ }^{2,3}$ and adults with $\mathrm{MS}^{4}$ Evidence in mice and humans further supports the notion that physical activity selectively increases dentate gyrus (DG) volume (DGv), perfusion, and neurogenesis. ${ }^{5}$ Currently, information is lacking regarding the association between MVPA and DGv in children with acquired demyelinating syndromes (ADSs), 20\% of whom are diagnosed with MS. Accelerometry is used widely in the pediatric population, including in children as young as 3 years of age, for objective documentation of physical activity. ${ }^{6,7}$ It is important to note that having patients wear an accelerometer for 7 days has been shown to be a reliable metric of usual physical activity in both healthy children and children with various chronic conditions. ${ }^{8,9} \mathrm{We}$ investigated the association between MVPA levels, quantified as average minutes per day of MVPA using 7-day accelerometry, and the DGv of pediatric patients with ADS, including those ascertained as having MS and those who remain as monophasic ADS (monoADS). We hypothesized that higher levels of MVPA would be associated with greater DGv. We also explored whether more modest physical activity intensities (sedentary and light physical activity) were associated with DGv in children with MS and monophasic demyelination.

\section{Methods}

\section{Study population}

This was a cross-sectional analysis of prospectively collected data on MS or monoADS patients recruited between 2014 and 2015 attending a specialized Pediatric MS Center. Standard definitions of MS and monophasic demyelinating disorders were followed. ${ }^{10}$ Patients with research MRI scan and accelerometry acquired within 30 days of one each other that passed quality assurance, and who had been followed up for a minimum of 2 years after incident demyelination, were enrolled. Patients who experienced a relapse or received corticosteroids within 30 days from study start were excluded from the present analysis.

\section{Clinical factors}

Demographic and clinical variables were collected using a standardized case report form. Disability (Expanded Disability Status Scale [EDSS]) and depression status (Centre for Epidemiological Studies Depression Scale for Children [CES-DC]), ${ }^{11} 2$ factors that may influence physical activity levels, were evaluated within 30 days of the accelerometry measure. CES-DC scores $\geq 15$ were considered suggestive of major depression. ${ }^{11}$

\section{Physical activity measurement}

Physical activity was measured according to a standardized 7-day protocol with accelerometry (ActiGraph 7,164 accelerometer; ActiGraph, Pensacola, FL) as described. ${ }^{12}$ Because physical activity levels are fairly stable in children within the same season, ${ }^{13,14}$ we assumed general stability of patterns of behavior over a period of 30 days in the absence of a specific intervention. To further mitigate concern regarding change in physical activity in the interval between accelerometry and imaging, we performed MRI scanning and accelerometry in close temporal relation.

Physical activity was classified based on the accelerometer counts as sedentary to vigorous, depending on the rate of energy consumption [1 Metabolic Equivalent of Task $(\mathrm{MET})=3.5 \mathrm{ml}$ / $\mathrm{kg} / \mathrm{min}$ of $\mathrm{O}_{2}$ consumption] estimated for a given count, sex, and age range. We followed validated accelerometry cutoff points calibrated with energy expenditure in children and youth aged 6 years and older. ${ }^{15}$ MVPA was measured in minutes per day and defined as physical activity exceeding 3,199 counts per minute $(\mathrm{CPM}) .{ }^{12}$ Sedentary and light physical activity were defined as activities below 100 and 3,199 CPM, respectively. ${ }^{15}$

\section{MRI}

The MRI protocol included (1) a sagittal T1-weighted, 3D spoiled gradient recalled echo sequence $(1.5 \times 1 \times 1 \mathrm{~mm}$; repetition time $(\mathrm{TR})=22 \mathrm{~ms}$; echo time $(\mathrm{TE})=8 \mathrm{~ms}$; flip angle $\left.=30^{\circ}\right)$; (2) a $2 \mathrm{D}$ axial dual-echo proton density-/T2-weighted fast spin-echo sequence $(1 \times 1 \times 2 \mathrm{~mm}$; TR $=3,500 \mathrm{~ms}$; TE1 $/$ $\mathrm{TE} 2=15 / 63 \mathrm{~ms}$; echo train length $=8)$; and $(3)$ an axial $2 \mathrm{D}$ multislice fluid-attenuated turbo inversion recovery sequence $(1 \times 1 \times 5 \mathrm{~mm}$; TR = 9,000 ms; TE = $100 \mathrm{~ms}$; TI = 2,250 ms $)$. After a 9-parameter linear registration based on intensity, crosscorrelation was performed as a similarity measure between each native T1-weighted volume and the ICBM152 template; a brain mask was extracted using a multiresolution nonlocal segmentation technique. Each brain mask was warped back onto each T1-weighted native space using the inverse transformations and used to compute the brain volume. ${ }^{16,17} \mathrm{~T} 2$ lesion volume (LV) were measured according to established pipelines. ${ }^{17}$ The manual tracing of the DG within the hippocampal body and tail was performed according to a standardized protocol ${ }^{18}$ (itksnap.org) by a single observer blinded to patients' clinical data, with computation of total (right + left) DGv normalized for brain size (normalized DGv [nDGv]). To test intraobserver reproducibility of DG segmentation, the scans of 10 randomly 
selected patients were evaluated twice, 2 weeks apart; the intraclass correlation coefficient was 0.89 .

\section{Statistical analysis}

SPSS (SPSS Inc, Release 23.0) was used to compute descriptive statistics based on the Fisher exact test, independent samples $t$ test, or Mann-Whitney $U$ test, where appropriate. Modeling was performed using Python (python.org) and the $\mathrm{R}$ (R Team, 2015) package lme4.

A general linear model was used to model the $\mathrm{nDGv}$ in each group (monoADS or MS):

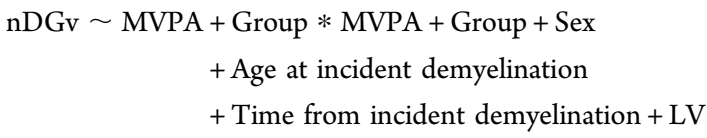

Our model takes into account multiple fixed factors and covariates including the daily minutes of MVPA, group (MS and monoADS), age at incident demyelination, time from incident demyelination, sex, and T2-LV. In particular, the term MVPA estimates the magnitude of the association between MVPA and nDGv in the MS group, whereas the interaction Group * MVPA estimates the additional effect in monoADS vs MS. We also tested separately the sum MVPA + Group * MVPA, which estimates the magnitude of the association in the monoADS group (table 1). We refit the model with the EDSS or depression status replacing LV to assess the effect of these factors, which are potentially correlated with each other. EDSS was treated as a categorical variable. Depression status was coded as a binary variable, equal to 1 if the CES-DC score was $\geq 15$ and
0 otherwise. Finally, we refit the model with sedentary activity or light physical activity replacing MVPA. Results were corrected for multiple comparisons (Bonferroni correction for 5 independent tests: adjusted $p=0.01)$.

\section{Standard protocol approvals, registrations, and patient consents}

Ethics approval was received from the Research Ethics Board at the Hospital for Sick Children, Toronto, Canada (REB\# 1000005356 and 1000042743). Written informed consent was obtained from all guardians and informed assent from all patients.

\section{Data availability}

Anonymized data will be shared by request from any qualified investigator.

\section{Results}

Eighteen patients with monoADS [acute disseminated encephalomyelitis $=8$, monofocal monoADS $=9$, and polyfocal monoADS $=1$ ] and 12 with MS (phenotype of initial presentation: transverse myelitis $=2$, optic neuritis $=3$, hemispheric syndromes $=3$, and brainstem syndromes $=4$ ) were included in the analysis. The median time between MRI and accelerometry was 1 day (interquartile range 1.3). Seven patients were excluded because of the elapsed time between accelerometry and research MRI exceeding 30 days. Pediatric MS patients were older at the time of incident demyelination, had a shorter elapsed time from incident demyelination, higher LV (as measured at the time of accelerometry), and lower daily MVPA with limited

Table 1 Results of the general linear model (reference group: MS)

\begin{tabular}{|c|c|c|c|}
\hline nDGv & & & \\
\hline Model goodness of fit: $F=4.159 ; p=0.00$ & & & \\
\hline Effect & Effect estimate $\left(\mathrm{mm}^{3}\right)$ & $95 \% \mathrm{Cl}$ & $p$ Value \\
\hline Intercept & 473 & $259-688$ & \\
\hline MVPA (MS) & -2.6 & -6.1 to 9.0 & 0.16 \\
\hline Group (monoADS) * MVPA & 5.0 & $1.6-8.4$ & 0.008 \\
\hline Group (monoADS) & -117 & -237 to 2.9 & 0.069 \\
\hline $\operatorname{Sex}(F)$ & -24.5 & -94 to 45 & 0.50 \\
\hline Age at incident demyelination [y] & -4.0 & -15 to 7.2 & 0.47 \\
\hline Time from incident demyelination [y] & -0.9 & -19 to 17 & 0.92 \\
\hline $\operatorname{LV}\left[\mathrm{cm}^{3}\right]$ & -4.1 & -12 to 3.7 & 0.31 \\
\hline MVPA + group (monoADS) * MVPA & 2.4 & $1.1-3.8$ & 0.0017 \\
\hline
\end{tabular}

Abbreviations: $\mathrm{Cl}$ = confidence interval; monoADS = monophasic acquired demyelinating syndrome; MS = multiple sclerosis; $\mathrm{nDGv}=$ total (left + right) normalized dentate gyrus volume; $\mathrm{F}=$ female; MVPA = moderate-to-vigorous physical activity per day; LV = brain lesion volume.

The effect estimate is the amount in $\mathrm{mm}^{3}$ of additional nDGv expected with a 1 -unit increase in the effect, and the $p$ measures the significance of that change. The " $\star^{\prime \prime}$ indicates an interaction. Patients with monoADS experienced an average $2.4 \mathrm{~mm}^{3}$ increase in nDGv with a 1-minute increase in MVPA [Group (monoADS) * MVPA interaction]. The term MVPA gives the estimated effect on nDGv in the MS group, whereas the interaction Group * MVPA is the difference between the MS and monoADS groups. The sum of these terms is the estimated effect in the monoADS group and is provided in the last row. 
Table 2 Demographic and clinical characteristics

\begin{tabular}{|c|c|c|c|}
\hline & MS & monoADS & $p$ Value $^{a}$ \\
\hline No. of patients & 12 & 18 & - \\
\hline Median clinical follow-up (IQR) [y] & $4.4(2.2)$ & $6(2.5)$ & 0.001 \\
\hline Females/males & $9 / 3$ & $7 / 11$ & 0.072 \\
\hline Mean age at incident demyelination (SD) [y] & $12.8(2.3)$ & $8(3.3)$ & 0.001 \\
\hline Median time from incident demyelination (IQR) [y] & $2.5(2)$ & $4.1(2.5)$ & 0.001 \\
\hline Median no. of clinical attacks (IQR) & $1.5(2)$ & $1(0)$ & 0.022 \\
\hline Median MVPA (IQR) [min/d] & $9.5(14)$ & $24.5(47)$ & 0.017 \\
\hline Median EDSS (IQR) & $1.3(1.3)$ & $1(1.1)$ & 0.346 \\
\hline Depressed/nondepressed & $4 / 12$ & $3 / 18$ & 0.392 \\
\hline Mean nDGv (SD) $\left[\mathrm{cm}^{3}\right]$ & $0.34(0.1)$ & $0.4(0.1)$ & 0.100 \\
\hline Median LV (IQR) $\left[\mathrm{cm}^{3}\right]$ & $2.5(10.8)$ & $0.1(0.01)$ & 0.001 \\
\hline No. of patients with >1 gadolinium-enhancing lesions (\%) & $3 / 12$ (25) & - & $-{ }^{b}$ \\
\hline
\end{tabular}

Abbreviations: monoADS = monophasic acquired demyelinating syndrome; IQR = interquartile range; MVPA = moderate-to-vigorous physical activity per day; $\mathrm{nDGV}=$ normalized dentate gyrus volume; $\mathrm{LV}=$ brain lesion volume; $\mathrm{SD}=$ standard deviation.

${ }^{a}$ Fisher exact test, independent samples $t$ test, and Mann-Whitney $U$ test, where appropriate.

b Unenhanced MRI scans were performed in all except one monoADS patients, who did not show any contrast enhancement after gadolinium administration.

variance compared with monoADS patients. nDGv did not differ significantly between groups (table 2). Ten of the 11 MS patients were being treated with a first-line diseasemodifying treatment $(\mathrm{DMT})$ at the time of the study (glatiramer acetate $=4$, interferon $\beta-1 \mathrm{a}=2$, interferon $\beta-1 \mathrm{~b}=1$, and dimethyl fumarate $=3$ ). Three of them received previous treatment with another injectable DMT (glatiramer acetate, interferon $\beta$-1a, or interferon $\beta$-1b). One MS patient, on natalizumab at the time of the study, previously received cyclophosphamide pulses. Our general linear model controlling for age at the time of incident demyelination, time from incident demyelination, sex, and LV showed that in the monoADS group, each one-minute increase in MVPA was associated with $2.4 \mathrm{~mm}^{3}$ larger nDGv $(p=0.0017)$. The estimated mean effect in the MS group was negative $\left(-2.6 \mathrm{~mm}^{3} / \mathrm{min}\right.$ increase in MVPA); however, this association was not significant $\left(R^{2}=0.19, p=0.16\right)$, likely a result of the small sample size and one outlying value. Consequently, our data do not allow the direction of an effect, if any, to be confidently ascertained. However, when we compared the magnitude of the association of MVPA with nDGv between groups, patients with MS showed significantly less increase in $\mathrm{nDGv}$ with increased MVPA than did those with monoADS $\left(5.0 \mathrm{~mm}^{3}\right.$ smaller nDGv increase per minute of MVPA in MS vs monoADS, $p=$ 0.008) (table 1, figure).

Neither the EDSS $\left(37 \mathrm{~mm}^{3} / \mathrm{min}\right.$ of MVPA for the EDSS score 1 vs $0, p=0.25 ;-12.5 \mathrm{~mm}^{3} / \mathrm{min}$ of MVPA for the EDSS score 2 vs $0, p=0.83)$ nor the presence or absence of depression $\left(56 \mathrm{~mm}^{3} / \mathrm{min}\right.$ of MVPA, $\left.p=0.073\right)$ was associated with the $\mathrm{nDGv}$. None of the models for sedentary or light physical activity was significant (sedentary physical activity: model goodness of fit: $\mathrm{F}=0.794 ; p=0.60$; adj. $\mathrm{R}^{2}=-0.052$; light physical activity: model goodness of fit: $F=1.194$; $p=0.35$; adj. $R^{2}=0.045$ ).

\section{Discussion}

Higher levels of MVPA in children with monophasic demyelination are associated with greater DG size, after adjusting for age at the time of incident demyelination, time from incident demyelination, sex, T2 lesion burden, physical disability, and depression. Children with monophasic demyelination recover well neurologically, have a very low rate of depression, and typically have a low burden of residual $\mathrm{T} 2$ lesions; thus, although these factors were considered, they did not influence our findings.

Previous studies have documented an association between MVPA and preservation of global hippocampal volume , $^{49-21}$ and improved memory function ${ }^{4,22}$ in adult MS patients. We did not find a statistically significant association between MVPA and $\mathrm{nDGv}$ in our pediatric MS patients $\left(-2.6 \mathrm{~mm}^{3}\right.$ for each 1-min increase in MVPA, $p=0.16$ ), likely in part due to the limited amount and level of physical activity. This is consistent with previous data indicating lower participation in physical activity in children with MS compared with both monoADS and healthy youth. ${ }^{12}$ However, our results leave open the possibility that the correlation between MVPA and DGv is, in fact, negative. Previous studies in adult relapsingremitting MS have shown hippocampal morphological changes consistent with increased DGv; this effect was not present in primary or secondary progressive $\mathrm{MS}^{23}$ This 
Figure Comparison between minutes of MVPA/day and $\mathrm{nDGV}$ in patients with MS (green) or monoADS (blue)

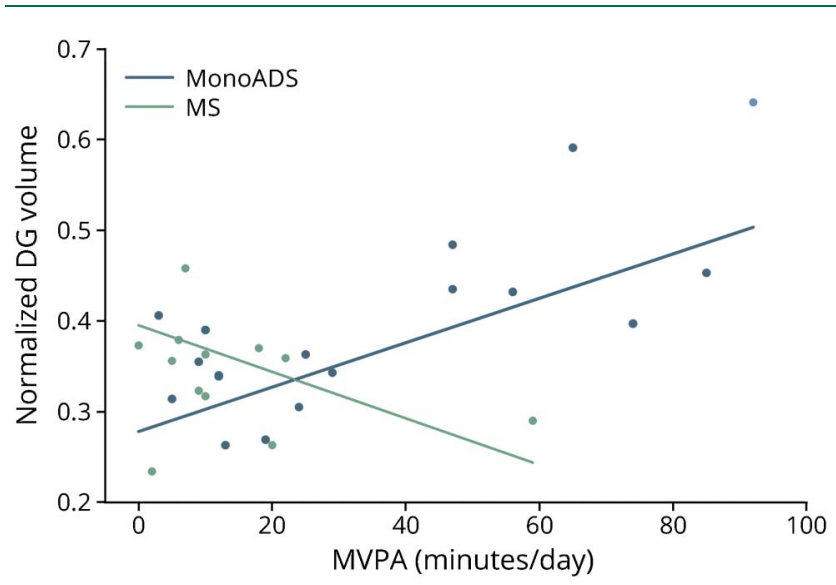

Patients with monoADS demonstrated a range of MVPA levels that correlated positively with $\mathrm{nDGv}\left(R^{2}=0.32 ; p=0.0016\right)$. Although the green line suggests an adverse effect of MVPA on nDGv, this association was not significant in the MS group $\left(R^{2}=0.19 ; p=0.16\right)$, likely a result of the small sample size and one outlying value. However, patients with MS showed significantly less increase in nDGv with increased MVPA than did those with monoADS $(p=0.008)$. monoADS $=$ monophasic acquired demyelinating syndrome; MVPA = moderate-to-vigorous physical activity; nDGv = normalized dentate gyrus volume.

observation suggests that the volume of the DG might increase in MS in response to inflammation. Our observation of a nonsignificant negative correlation between MVPA and $\mathrm{nDGv}$ may thus hint to an anti-inflammatory effect of physical activity within the DG of patients with MS. We computed that a study with 37 patients with MS would be required to confirm a negative correlation between MVPA and $\mathrm{nDGv}$ of the magnitude we observed (one-tailed $t$ test, $\beta=0.8$ ). ${ }^{24}$ In future studies, more specific MR measures than DGv may be required. Possibilities include evaluation of changes in cellularity and water content $^{25}$ or tissue microstructure. ${ }^{26}$ Of note, the MS group did not differ from the monoADS patients in terms of physical disability (maximum EDSS score $=2$ in both the MS and monoADS groups). Thus, the limited amount of MVPA in the MS group and, arguably, the lack of a statistically significant association between MVPA and $\mathrm{nDGv}$ were not due to greater physical disability. Flu-like symptoms are a common side effect of beta interferons therapy, which may have limited physical activity engagement in our MS patients. However, only three of 11 were receiving such treatment at the time of the study. A study of 29 adult MS patients with depression demonstrated an association between depression and smaller DG/Cornu Ammonis 2-3 volume. ${ }^{27}$ We did not detect depression as a significant contributing factor in our patients, probably because of the low sample size and the low frequency of depression within our MS group. Other studies have shown an association between depression and reduced participation in physical activity in adolescents with MS. ${ }^{12}$ Future studies are needed to sort out the complex relationship between depression, physical activity, and DGv in this population.
In addition to consideration of patient-based experiential factors, we also evaluated relationships between $\mathrm{nDGv}$ and MS disease activity (LV). Both in adults ${ }^{28}$ and children, ${ }^{1}$ moderate direct correlations have been documented between LV and morphological changes of the DG surface suggestive for DG hypertrophy of uncertain significance. ${ }^{1,23}$ Our analysis did not reveal a significant association between LV and DGv. This may have been due to the different techniques applied (DG segmentation and volumetry vs radial mapping analysis) or the smaller sample size of our study.

The cross-sectional, observational nature of this study did not allow us to draw a causal or mechanistic relationship between increased MVPA and $\mathrm{nDGv}$ in children with monophasic demyelination. However, many studies support the biological plausibility of this finding. On a histologic level, animal studies have shown that voluntary wheel running selectively increases neurogenesis, $5,29,30$ angiogenesis, ${ }^{5,31}$ and dendritic complexity $^{32,33}$ within the DG. Within the hippocampus, voluntary wheel running is also known to increase the secretion of neurotrophic factors ${ }^{2,34}$ and anti-inflammatory cytokines. ${ }^{3}$ Increased MVPA levels may thus reduce inflammatory injury and/or promote repair after acute demyelination. In children with monophasic demyelination, the absence of ongoing inflammation may lead to a permissive environment for MVPA to supply a trophic stimulus. In the context of MS, however, the ability of MVPA to modulate inflammation-related injury may be challenged by persistent pathologic processes, both inflammatory and degenerative. Our finding of significantly less increase in $\mathrm{nDGv}$ with increased MVPA in the MS patients compared with the monoADS group seems to support this notion. In particular, recent work suggests a pattern of microglial activation within the DG, which is associated with selective neurodegeneration, alteration in synaptic transmission, and memory impairment in mice with early experimental MS. ${ }^{35}$ It is thus possible that increasingly effective immune-modulating therapies, which lead to a reduction in MRI and clinical burden of inflammatory disease, may facilitate the benefit of physical activity in patients with MS.

As an alternative explanation for the different strength of the association of MVPA with $\mathrm{nDGv}$ between groups, the effect of MVPA on DGv may occur in the context of higher levels of daily MVPA (similar to that observed in our monoADS group), or increments in DGv may proceed in a nonlinear fashion, with smaller increases for patients with lower daily MVPA. Therefore, the limited participation in MVPA in our MS group may have limited our ability to detect its relationship with $\mathrm{nDGv}$. Importantly, the hippocampus is involved in the complex cognitive processing associated with certain kinds of physical activity and exploratory behavior. ${ }^{36}$ To follow this argument, we cannot exclude reverse causality-specifically, the possibility that MS-related insult to hippocampal structure and function led to reduced engagement in physical activity in our MS group.

Hippocampal subfield segmentation is feasible in children and adolescents using the 3D-T1 $1.5 \mathrm{~T}$ sequences acquired, ${ }^{37}$ but 
our DG measures would have been enhanced by hippocampal-targeted high-resolution sequences. Future longitudinal studies should evaluate the effects of physical activity levels on age-expected regional and whole brain growth over time, which has been recently found to be affected even in children with monophasic demyelination. ${ }^{38}$

We show that moderate to vigorous exercise associates with increased size of the DG in children who have recovered from monophasic demyelination. Our results also show that the relationship between MVPA and DGv in MS may be more complicated, possibly confounded by other factors, such as inflammation or therapy; more specific imaging techniques may be required to quantify these factors. Longitudinal design with controlled intervention would also reduce confounding factors.

\section{Author contributions}

G. Longoni: study concept and design, analysis and interpretation of data, and drafting of the manuscript. R. A. Brown: analysis and interpretation of data and critical revision of the manuscript for intellectual content. B. Aubert-Broche: analysis and interpretation of data. S.A. Grover: data acquisition and critical revision of the manuscript for intellectual content. $\mathrm{H}$. Branson: data acquisition and critical revision of the manuscript for intellectual content. D. Fetco: analysis of data and critical revision of the manuscript for intellectual content. A. Bar-Or, critical revision of the manuscript for intellectual content and funding for the research. R.A. Marrie: critical revision of the manuscript for intellectual content and funding for the research. R. W. Motl: critical revision of the manuscript for intellectual content. D.L. Collins: critical revision of the manuscript for intellectual content. S. Narayanan: critical revision of the manuscript for intellectual content. D.L. Arnold: critical revision of the manuscript for intellectual content and funding for the research. B.L. Banwell: study concept and design, critical revision of the manuscript for intellectual content, and funding for the research. E.A. Yeh: study concept and design, critical revision of the manuscript for intellectual content, and funding for the research.

\section{Study funding}

Supported by funds from the Multiple Sclerosis Scientific Research Foundation, Multiple Sclerosis Society of Canada, the Mario Batali Foundation, and SickKids Foundation, Toronto, Canada.

\section{Disclosure}

G. Longoni received research support from the National Multiple Sclerosis Society. R.A. Brown served on the scientific advisory board of Biogen and consulted for NeuroRx Research, Biogen, and Multiple Sclerosis Society of Canada. B. Aubert-Broche reports no disclosures. S.A. Grover reports no disclosures. H. Branson reports no disclosures. D. Fetco reports no disclosures. A. Bar-Or served on the scientific advisory boards of Receptos-Celgene, Sanofi-Genzyme, Roche/ Genentech, Novartis, GSK, Guthy-Jackson Greater Good Foundation, and Immune Tolerance Network; received travel funding and/or speaker honoraria from Receptos-Celgene, Roche/Genentech, Novartis, Sanofi-Genzyme, and GSK; is on the editorial board of Neurology and Clinical and Experimental Neuroimmunology; consulted for Receptos-Celgene, Roche/Genentech, Novartis, Sanofi-Genzyme, and GSK; and received research support from Novartis, Genzyme-Sanofi, and Biogen. R.A. Marrie served on the editorial boards of Neurology and Multiple Sclerosis Journal and received research support from the Canadian Institutes of Health Research, Research Manitoba, Waugh Family Chair in Multiple Sclerosis, Multiple Sclerosis Society of Canada, National Multiple Sclerosis Society, Multiple Sclerosis Scientific Foundation, Consortium of Multiple Sclerosis, and Crohn's and Colitis Canada. R.W. Motl received honorarium from the Consortium of MS Centers; served as an associate editor of Neurorehabilitation and Neural Repair; and received research support from EMD Serono and NMSS. D.L. Collins consulted for NeuroRx Research and received research support from the Multiple Sclerosis Society of Canada. S. Narayanan received speaker honoraria from Novartis Canada; consulted for NeuroRx Research; and received research support from the Canadian Institute of Health Research, International Progressive MS Alliance, Multiple Sclerosis Society of Canada Scientific Research Foundation, Multiple Sclerosis Society of Canada, and Myelin Repair Foundation. D.L. Arnold received travel funding from Genzyme, Progressive MS Alliance, and End MS; consulted for Acorda, Biogen, Celgene, GeNeuro, Genentech, Genzyme, Novartis, Receptos, Roche, Sanofi, Teva, and Wave Life Sciences; received research support from Biogen, Novartis, CIHR, International Progressive MS Alliance, and Multiple Sclerosis Research Foundation; and holds stock or stock options from NeuroRx. B.L. Banwell served on the scientific advisory boards of Biogen, Sanofi, Eli Lilly, and Novartis; served on the editorial board of Neurology; consulted for Novartis; spoke at an event by Consortium of MS Centers, the Corpus, and Medscape; and received research support from the Multiple Sclerosis Society of Canada, Multiple Sclerosis Scientific Research Foundation, and National Multiple Sclerosis Society. E.A. Yeh served on the scientific advisory board of ACI Services; served on the editorial board of Neurology; and received research support from CIHR, PCORI, CMSMS, MS Monitoring System, National MS Society, the Mario Batali Foundation, MS Society (Canada), Dairy Farmers of Ontario, SickKids Innovation Fund, MS Research Foundation, and Rare Diseases Foundation. Full disclosure form information provided by the authors is available with the full text of this article at Neurology. org/NN.

Received February 20, 2018. Accepted in final form July 19, 2018.

\section{References}

1. Rocca MA, Morelli ME, Amato MP, et al. Regional hippocampal involvement and cognitive impairment in pediatric multiple sclerosis. Mult Scler 2016;22: 628-640.

2. Erickson KI, Voss MW, Prakash RS, et al. Exercise training increases size of hippocampus and improves memory. Proc Natl Acad Sci USA 2011;108:3017-3022.

3. Gleeson M, Bishop NC, Stensel DJ, Lindley MR, Mastana SS, Nimmo MA. The antiinflammatory effects of exercise: mechanisms and implications for the prevention and treatment of disease. Nat Rev Immunol 2011;11:607-615. 
4. Leavitt VM, Cirnigliaro C, Cohen A, et al. Aerobic exercise increases hippocampal volume and improves memory in multiple sclerosis: preliminary findings. Neurocase 2014;20:695-697.

5. Pereira AC, Huddleston DE, Brickman AM, et al. An in vivo correlate of exerciseinduced neurogenesis in the adult dentate gyrus. Proc Natl Acad Sci USA 2007;104: 5638-5643.

6. Puyau MR, Adolph AL, Vohra FA, Butte NF. Validation and calibration of physical activity monitors in children. Obes Res 2002;10:150-157.

7. Beets MW, Bornstein D, Dowda M, Pate RR. Compliance with national guidelines for physical activity in U.S. preschoolers: measurement and interpretation. Pediatrics 2011;127:658-664.

8. Mackintosh KA, Ridgers ND, Evans RE, McNarry MA. Physical activity and sedentary time patterns in children and adolescents with cystic fibrosis and age- and sex-matched healthy controls. J Phys Act Health 2018;15:82-88.

9. Jago R, Solomon-Moore E, Macdonald-Wallis C, Thompson JL, Lawlor DA, Sebire SJ. Association of parents' and children's physical activity and sedentary time in year 4 (8-9) and change between year 1 (5-6) and year 4: a longitudinal study. Int J Behav Nutr Phys Act 2017;14:110.

10. Krupp LB, Tardieu M, Amato MP, et al. International Pediatric Multiple Sclerosis Study Group criteria for pediatric multiple sclerosis and immune-mediated central nervous system demyelinating disorders: revisions to the 2007 definitions. Mult Scler J 2013;19:1261-1267.

11. Fendrich M, Weissman MM, Warner V. Screening for depressive disorder in children and adolescents: validating the center for epidemiologic studies depression scale for children. Am J Epidemiol 1990;131:538-551.

12. Grover SA, Sawicki CP, Kinnett-Hopkins D, et al. Physical activity and its correlates in youth with multiple sclerosis. J Pediatr 2016;179:197-203.e2.

13. Nyberg G, Ekelund U, Marcus C. Physical activity in children measured by accelerometry: stability over time. Scand J Med Sci Sports 2009;19:30-35.

14. Quante M, Wang R, Weng J, et al. Seasonal and weather variation of sleep and physical activity in 12-14-year-old children. Behav Sleep Med 2017:1-13.

15. Kinnett-Hopkins D, Grover SA, Yeh EA, Motl RW. Physical activity in pediatric onset multiple sclerosis: validating a questionnaire for clinical practice and research. Mult Scler Relat Disord 2016;10:26-29.

16. Eskildsen SF, Coupe P, Fonov V, et al. BEaST: brain extraction based on nonlocal segmentation technique. Neuroimage 2012;59:2362-2373.

17. Aubert-Broche B, Fonov VS, Garcia-Lorenzo D, et al. A new method for structural volume analysis of longitudinal brain MRI data and its application in studying the growth trajectories of anatomical brain structures in childhood. Neuroimage 2013;82:393-402.

18. Yushkevich PA, Avants BB, Pluta J, et al. A high-resolution computational atlas of the human hippocampus from postmortem magnetic resonance imaging at 9.4 T. Neuroimage 2009; 44:385-398.

19. Motl RW, Pilutti LA, Hubbard EA, Wetter NC, Sosnoff JJ, Sutton BP. Cardiorespiratory fitness and its association with thalamic, hippocampal, and basal ganglia volumes in multiple sclerosis. Neuroimage Clin 2015;7:661-666.

20. Klaren RE, Hubbard EA, Motl RW, Pilutti LA, Wetter NC, Sutton BP. Objectively measured physical activity is associated with brain volumetric measurements in multiple sclerosis. Behav Neurol 2015;2015:482536
21. Prakash RS, Snook EM, Motl RW, Kramer AF. Aerobic fitness is associated with gray matter volume and white matter integrity in multiple sclerosis. Brain Res 2010;1341:41-51.

22. Sandroff BM, Hillman CH, Benedict RH, Motl RW. Acute effects of walking, cycling, and yoga exercise on cognition in persons with relapsing-remitting multiple sclerosis without impaired cognitive processing speed. J Clin Exp Neuropsychol 2015;37: 209-219.

23. Rocca MA, Longoni G, Pagani E, et al. In vivo evidence of hippocampal dentate gyrus expansion in multiple sclerosis. Hum Brain Mapp 2015;36:4702-4713.

24. Faul F, Erdfelder E, Buchner A, Lang AG. Statistical power analyses using G*Power 3.1: tests for correlation and regression analyses. Behav Res Methods 2009;41: $1149-1160$.

25. Zhang H, Schneider T, Wheeler-Kingshott CA, Alexander DC. NODDI: practical in vivo neurite orientation dispersion and density imaging of the human brain. Neuroimage 2012;61:1000-1016.

26. Longoni G, Brown RA, MomayyezSiahkal P, et al. White matter changes in paediatric multiple sclerosis and monophasic demyelinating disorders. Brain 2017;140: $1300-1315$.

27. Gold SM, Kern KC, O'Connor MF, et al. Smaller cornu ammonis 2-3/dentate gyrus volumes and elevated cortisol in multiple sclerosis patients with depressive symptoms. Biol Psychiatry 2010;68:553-559.

28. Longoni G, Rocca MA, Pagani E, et al. Deficits in memory and visuospatial learning correlate with regional hippocampal atrophy in MS. Brain Struct Funct 2015;220: 435-444.

29. van Praag H, Christie BR, Sejnowski TJ, Gage FH. Running enhances neurogenesis, learning, and long-term potentiation in mice. Proc Natl Acad Sci USA 1999;96: 13427-13431.

30. Speisman RB, Kumar A, Rani A, Foster TC, Ormerod BK. Daily exercise improves memory, stimulates hippocampal neurogenesis and modulates immune and neuroimmune cytokines in aging rats. Brain Behav Immun 2013;28:25-43.

31. Maass A, Duzel S, Goerke M, et al. Vascular hippocampal plasticity after aerobic exercise in older adults. Mol Psychiatry 2015;20:585-593.

32. Redila VA, Christie BR. Exercise-induced changes in dendritic structure and complexity in the adult hippocampal dentate gyrus. Neuroscience 2006;137: 1299-1307.

33. Eadie BD, Redila VA, Christie BR. Voluntary exercise alters the cytoarchitecture of the adult dentate gyrus by increasing cellular proliferation, dendritic complexity, and spine density. J Comp Neurol 2005;486:39-47.

34. Vaynman S, Ying Z, Gomez-Pinilla F. Exercise induces BDNF and synapsin I to specific hippocampal subfields. J Neurosci Res 2004;76:356-362.

35. Planche V, Panatier A, Hiba B, et al. Selective dentate gyrus disruption causes memory impairment at the early stage of experimental multiple sclerosis. Brain Behav Immun 2017;60:240-254.

36. Kempermann G. New neurons for 'survival of the fittest'. Nat Rev Neurosci 2012;13: 727-736.

37. Krogsrud SK, Tamnes CK, Fjell AM, et al. Development of hippocampal subfield volumes from 4 to 22 years. Hum Brain Mapp 2014;35:5646-5657.

38. Aubert-Broche B, Weier K, Longoni G, et al. Monophasic demyelination reduces brain growth in children. Neurology 2017;88:1744-1750. 


\section{Neurology \\ Neuroimmunology \& Neuroinflammation}

\section{Physical activity and dentate gyrus volume in pediatric acquired demyelinating syndromes}

Giulia Longoni, Robert A. Brown, Berengere Aubert-Broche, et al.

Neurol Neuroimmunol Neuroinflamm 2018;5;

DOI 10.1212/NXI.0000000000000499

This information is current as of September 6, 2018

\section{Updated Information \& \\ Services}

References

Subspecialty Collections

Permissions \& Licensing

Reprints including high resolution figures, can be found at:

http://nn.neurology.org/content/5/6/e499.full.html

This article cites 37 articles, 3 of which you can access for free at: http://nn.neurology.org/content/5/6/e499.full.html\#\#ref-list-1

This article, along with others on similar topics, appears in the following collection(s):

Volumetric MRI

http://nn.neurology.org//cgi/collection/volumetric_mri

Information about reproducing this article in parts (figures,tables) or in its entirety can be found online at:

http://nn.neurology.org/misc/about.xhtml\#permissions

Information about ordering reprints can be found online: http://nn.neurology.org/misc/addir.xhtml\#reprintsus

Neurol Neuroimmunol Neuroinflamm is an official journal of the American Academy of Neurology.

Published since April 2014, it is an open-access, online-only, continuous publication journal. Copyright

Copyright $\odot 2018$ The Author(s). Published by Wolters Kluwer Health, Inc. on behalf of the American

Academy of Neurology.. All rights reserved. Online ISSN: 2332-7812.

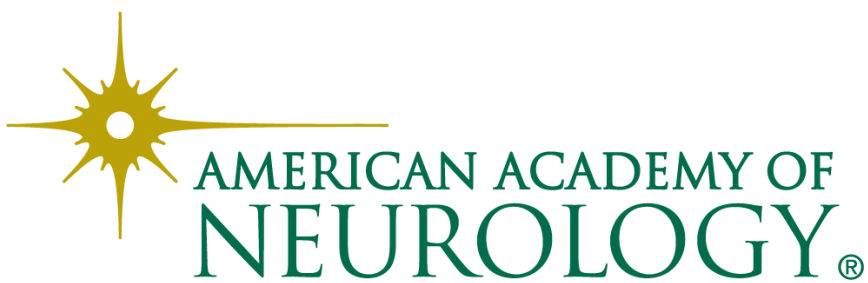

